\title{
The Impact of Volatility and Net Buying Pressure on the Trading Demand of Speculators and Hedgers
}

\section{Chuang-Chang Chang, Pei-Fang Hsieh and Zih-Ying Lin*}

\begin{abstract}
We investigate the ways in which the net buying pressure of options and the volatility of the underlying asset affect the trading demand for speculation and hedging in TAIEX options. We place particular focus on an examination of whether any changes were discernible in the volatility effects after the 2007 subprime mortgage crisis, and find that volatility seems to have had little significant impact on the trading demand of either speculators or hedgers; however, the net buying pressure of OTM calls and ATM puts are found to provide significant explanatory power on the trading demand of both types of investors. Furthermore, a significant change is found after the subprime crisis in the trading activities of speculators, who are generally found to have become more risk-averse, resulting in a reduction in their option positions when there is any sharp increase in risk in the underlying asset.
\end{abstract}

Keywords: Trading demand; Volatility; Speculator; Hedger; Net buying pressure.

July 2013

\footnotetext{
${ }^{*}$ Chuang-Chang Chang and Zih-Ying Lin are collocated at the Department of Finance, National Central University, Taiwan; and Pei-Fang Hsieh (the corresponding author) is at the Department of Quantitative Finance, National Tsing Hua University, Taiwan. Address for correspondence: Department of Quantitative Finance, National Tsing Hua University, 101 Kuang-Fu Road, Section 2, Hsinchu, Taiwan 30013, ROC. Tel: 03-5162132; email: pfhsieh@mx.nthu.edu.tw. We are grateful for the helpful comments provided by Ji-Chai Lin and to the seminar participants at National Central University.
} 


\section{Introduction}

Several prior studies have demonstrated that trading activities in the derivatives market can directly affect the level of volatility in the price of the underlying asset; and indeed, a positive association has also been reported between trading volume and volatility in the futures market, within which a negative association was found between open interest and volatility (Bessembinder and Seguin, 1992).

Similar investigations were carried out by both Wang (2002) and Pan, Liu and Roth (2003), with their studies providing much more precise identification of trading activities. These studies, both of which found that the trading demand in the futures market was correlated with price volatility, contributed to the extant literature in this field by identifying the trading demand based on different types of traders. They subsequently went on to provide further evidence of the diverse effects that volatility in the futures markets has on the trading demand of hedgers and speculators.

There is widespread recognition that the outbreak of the subprime mortgage crisis in the US subsequently led to the eruption of a severe financial 'tsunami' with enormous impacts on the global financial markets; several studies have noted that the subprime crisis has also led to significant changes in the behavior of investors. For example, based upon an examination of the Taiwan Stock Exchange Capitalization Weighted Stock Index (TAIEX) options data, Shiu, Pan, Lin and $\mathrm{Wu}$ 
(2010) investigated the impact of net buying pressure on changes in implied volatility in the pre- and post-subprime crisis periods and found that the shape of the implied volatility curve (investor behavior) had changed significantly in the postsubprime crisis period. In a very recent study, having set out to identify the changes in the risk-neutral probability density reflecting the price expectations of investors and their risk preferences, Birru and Figlewski (2012) found that the risk-neutral probability density was negatively skewed, with a left tail, and that this had changed dramatically during the financial crisis period.

Several researchers have examined the ways in which the volatility of the underlying asset affects the trading activity in the derivative markets. Chatrath, Ramchander and Song (1995b) found that the cash market volatility increased is due to an increase in the level of option trading. Besides, Hagelin (2000) considered the relationship between cash market volatility and option trading under different market conditions. Park, Switzer and Bedrossian (1999) used the most activity traded equity options to investigate the relationship between trading activity of stock options and the volatilities of the underlying stocks. However, since these studies were undertaken prior to the outbreak of the subprime mortgage crisis, it seems natural to question whether there may have been any change in the positive association between the volatility of the underlying asset and the trading demand for 
derivatives around the subprime crisis period. ${ }^{1}$ In addition, previous studies did not consider the different types of traders. We are therefore motivated to carry out an examination in this study of the ways in which the volatility of the underlying asset may have affected the trading demand for hedgers and speculators in the pre- and post-subprime mortgage crisis periods.

The net buying pressure of options has been found to play an important role in determining the trading demand for hedging and/or speculation in the derivatives markets; indeed, based upon a theoretical framework, Cao and Ou-Yang (2009) demonstrated that options trading revealed diverse opinions amongst traders with regard to information on current and subsequent periods. Current-period information, as measured by the differences in the demand for marketwise trades, such as net buying pressure, will be immediately revealed in trading activities; conversely, if the trading demand contains information on future volatility, after controlling for net buying pressure, such volatility is unlikely to have any effect on trading demand.

It is noted in both Bollen and Whaley (2004) and Shiu et al. (2010) that net buying pressure represents the temporary order imbalance between the supply and demand for options, since this imbalance has impacts on implied volatility; therefore, it may be important for us to consider this when studying those factors affecting

1 See Chaput and Ederington (2003, 2005), Ni, Pan and Poteshman (2008), Chang, Hsieh and Wang (2010) and Fehlenbrach and Sandas (2010). 
trading demand for hedging and/or speculation in the derivative markets. We should, however, emphasize that net buying pressure is generally regarded as the control variable for the different opinions amongst traders on current information, which could help to distinguish between the effects of temporary and permanent information on the trading demand of investors in the present study.

In contrast to many of the prior studies where analysis is invariably undertaken on the ways in which the volatility of the underlying asset affects the trading demand for hedging and speculation in the futures market, in the present study, we aim to investigate this issue in the options market, since the volatility of the underlying asset is likely to have a much more significant impact on trading demand. ${ }^{2}$

We employ data on all trades involving TAIEX options between July 2006 and December 2008 in an attempt to determine the effects of the volatility and net buying pressure of options on hedging and speculative trading demand in the options market in the pre- and post-subprime crisis periods. TAIEX options contracts, the details of which are obtained from the Taiwan Futures Exchange (TAIFEX), are the most actively traded options contracts in the world. ${ }^{3}$

In order to ensure that we obtain enhanced volatility estimations, we also

\footnotetext{
2 See Chaput and Ederington (2003, 2005), Ni, Pan and Poteshman (2008), Chang, Hsieh and Wang (2010) and Fehlenbrach and Sandas (2010).

3 According to the 2011 Statistics Section and Derivatives Market Survey (available at the World Federation of Exchanges website: http://www.world-exchanges.org/) the TAIEX options market is ranked fifth on a global scale in terms of frequency of trading in index stock options.
} 
introduce the concept of model-free implied volatility, developed by Jiang and Tian (2005, 2007). The advantage of using the model-free approach for the estimation of volatility is that this eliminates the potential problem of model misspecification; hence, we use a more precise volatility measure in this study which strengthens the robustness of our results on the impact of volatility on trading demand.

Our findings are summarized as follows. Firstly, we show little evidence of any significant impact of volatility on the trading demand of either speculators or hedgers; however, the temporary order imbalance measure (net buying pressure) is found to have explanatory power on the trading demand of both speculators and hedgers, particularly with regard to the net buying pressure of OTM calls and ATM puts. Secondly, we find some evidence of changes in the trading activities of speculators following the 2007 subprime mortgage crisis. These results imply that speculators have generally become more risk-averse, as a result of which there now appears to be a tendency amongst such traders to reduce their options positions when there is a sharp rise in the risk of the underlying asset.

Our study contributes to the related literature in several ways. Firstly, we simultaneously examine the ways in which the volatility of the underlying asset and net buying pressure of options affect trading demand for hedging and speculation in TAIEX options. Secondly, we examine the effects of the volatility in the underlying 
asset on the trading demand for hedgers and speculators in the pre- and post-subprime crisis periods. Thirdly, we introduce an improved estimation model, incorporating model-free implied volatility, which enhances the robustness of our results in the investigation of the impact of volatility on trading demand.

The remainder of this paper is organized as follows. The data adopted for this study is described in Section 2, followed in Section 3 by an explanation of our empirical methodology. The empirical results are subsequently discussed in Section 4. Finally, the conclusions drawn from this study are presented in Section 5.

\section{Data}

The Taiwan Futures Exchange (TAIFEX) provides daily summaries of open interest on the top 10 per cent of all trades (measured in terms of trade size) for both general investors and specific institutional investors in the TAIEX options market; ${ }^{4}$ according to the method of classification for institutional investors, these are investors with a specific demand for trading in TAIEX options. ${ }^{5}$

Hedgers were classified by Pan et al. (2003) as large commercial investors, whilst speculators were regarded as large non-commercial investors; open interest involving large trades by specific institutional investors is therefore seen in this

4 See the Taiwan Futures Exchange website: http://www.taifex.com.tw/eng/index.asp.

5 Specific institutional investors include dealers, foreign institutional investors, investment trusts, the National Stabilization Fund, the public service pension fund, the labor pension fund, the labor insurance fund, the postal savings deposit fund, financial institutions, insurance companies and hedged accounts. According to the classification of these specific traders, they are invariably referred to as 'commercial traders'. 
study as being undertaken for hedging purposes, whilst large trades involving general investors are regarded as being undertaken for speculative purposes. ${ }^{6}$

The time-series data on open interest for large trades by both general investors and specific institutional investors are obtained from the Taiwan Economic Journal (TEJ) database, with the sample period running from 3 July 2006 to 31 December 2008, a period surrounding the onset of the 2007 subprime mortgage crisis. We follow Shiu et al. (2010) to use 31 July 2007 as the date of the outbreak of the subprime crisis, and therefore define Sub-period I as the period from July 2006 to July 2007, and Sub-period II as the period from August 2007 to December 2008.

The summary statistics on open interest involving net speculative activities for long $(S L)$ and short $(S S)$ positions, and open interest involving hedging purposes for long $(H L)$ and short $(H S)$ positions are provided in Table 1. Long open interest comprises of open interest for long call positions and short put positions, whilst short open interest comprises of open interest for short call positions and long put positions.

<Table 1 is inserted about here>

We follow the definition of the trading demand for speculative activities proposed in Working (1960), with net speculative positions (SI) being defined as

\footnotetext{
6 One may, however, question this general classification; according to 2006-2008 TAIFEX trading statistics, the major participants in the TAIEX options market were individual investors, whose trading volume accounted for approximately 80 per cent of total market volume (excluding the volume provided by market makers). Nevertheless, since we know that market makers are usually neutral in the market, and therefore, their open interest is approximated to zero, it is reasonable to measure speculative activities using this classification.
} 
$1+S L /(H L+H S) \ldots$ if $H L \geq H S$, and as $1+S S /(H L+H S) \ldots$ if $H L<H S$. The trading demand for hedging purposes, which is constructed in the present study using the hedging pressure $(H P)$ variable proposed by de Roon, Nijman and Veld (2000), is defined as $(H S-H L) /(H L+H S)$.

Our observations on the full sample reveal that long open interest for both speculative activities and hedging purposes is greater than the corresponding short open interest. For both speculative activities and hedging purposes, short open interest is generally found to have been greater than long open interest during Sub-period I; however, this was subsequently reversed in Sub-period II, with long open interest having become greater than short open interest.

Table 1 also reveals diverse trading demand for speculative activities between Sub-period I and Sub-period II. Our results clearly indicate a significant reduction in the average speculative trading demand in the post-subprime crisis period, with the mean values of SI being 2.6836 in Sub-period I, and 1.9224 in Sub-period II. Conversely, the net positions of hedgers appear to be relatively close to neutral in the post-subprime crisis period, with the mean values of $H P$ being -0.0462 in Sub-period I, and -0.0013 in Sub-period II. These findings would seem to imply that the subprime mortgage crisis has given rise to changes in the trading activities of both hedgers and speculators. 
Our investigation of the temporary order imbalance between supply and demand in the options market is facilitated by following the approach adopted by Shiu et al. (2010), since this appears to be better suited to the TAIEX options trading system. All of the options data, covering our full sample period from July 2006 to December 2008, are collected from the TEJ database, and in order to simplify the calculation of net purchases, we select two categories of moneyness, at-the-money (ATM) and out-of-the-money (OTM) options. ${ }^{7}$

The calculation of the net purchases for each options contract in this study is based upon the total number of buyer-initiated contracts minus the total number of seller-initiated contracts. ${ }^{8}$ Net buying pressure $(N B P)$ refers to the equally-weighted average of the Delta-weighted net purchases across all options contracts belonging to each moneyness category, as follows:

$$
\begin{gathered}
\text { Net buying pressure }{ }^{M}=\frac{1}{N} \sum_{i=1}^{N} \\
\text { Net purchase of option contract }{ }_{i} \times \mid \text { Delta }_{i} \mid
\end{gathered}
$$

where $N$ is the number of options contracts belonging to each of the moneyness categories, $M=\mathrm{ATM}$ and OTM; and Delta $i$ is computed by $N\left(d_{1}\right) /-N\left(-d_{1}\right)$, which is modified from the Black-Scholes model.

The volatility estimate is the annualized volatility of the previous trading day,

\footnotetext{
7 The ratio of the strike price to the underlying price is in the range of 0.965 to 1.035 for ATM calls and puts, 0.895 to 0.965 for OTM puts, and 1.035 to 1.105 for OTM calls.

8 The determination of buyer- and seller-initiated trades follows the Lee and Ready (1991) algorithm.
} 
which is calculated as:

$$
\sigma_{\mathrm{t}-1}=\sqrt{252 * \sum_{\mathrm{k}=1}^{54} \varepsilon_{\mathrm{k}, \mathrm{t}-1}^{2}}
$$

where $\varepsilon_{k, t-1}$ refers to the return innovations at the $k^{\text {th }}$ five-minute interval on day $t-1$.

The summary statistics on the net purchases of options contracts (NPC) and net buying pressure $(N B P)$ for ATM and OTM options are reported in Table 2, where the negative $N P C$ indicates that net seller-initiated trades are larger than net buyerinitiated trades. As the table shows, net selling of ATM call options during Sub-period I is found to have been significantly greater than that during Sub-period II, whilst net selling of OTM call options during Sub-period II is found to have surpassed that of Sub-period I.

$<$ Table 2 is inserted about here $>$

OTM call options are generally used more than ATM call options to hedge spot positions; however, a significant increase in the net selling of OTM call options is clearly discernible in Sub-period II. There has also been an obvious reduction in the net selling of both ATM and OTM put options over the same period. The summary statistics on $N B P$ provide further confirmation of this trend, since we find that the NBP of OTM calls is negative, thereby implying the net selling of OTM call options for hedging purposes. Conversely, a significant reduction in the NBP of ATM and OTM put options is found in the post-subprime crisis period. 


\section{Methodology}

\subsection{Volatility Estimates}

Three volatility estimates are used in the current study: (i) model-free volatility; (ii) conditional volatility; and (iii) realized volatility. The options data used to estimate model-free volatility follow the sample criteria of Jiang and Tian $(2005),{ }^{9}$ with the cubic spline method being used to fit a smooth surface of Black-Scholes implied volatility from the available option transaction prices. ${ }^{10}$

The range of strike prices, calculated from the available option transaction prices, are defined as $\left[K_{\min }, K_{\max }\right]$, where $0<K_{\min }<S_{0}<K_{\max }<+\infty$. Model-free implied variance is therefore expressed as:

$$
2 \int_{K_{\min }}^{K_{\max }} \frac{C(T, K)-\max \left(0, S_{0}-K\right)}{K^{2}} d K
$$

where $S_{t}$ and $C(T, K)$ respectively denote the underlying asset and option prices with strike price $K$ and time to maturity $T$.

The numerical integration of Equation (3), using the trapezoidal rule, can be expressed as:

$$
2 \int_{K_{\min }}^{K_{\max }} \frac{C(T, K)-\max \left(0, S_{0}-K\right)}{K^{2}} d K \approx \sum_{i=1}^{m}\left[g\left(T, K_{i}\right)+g\left(T, K_{i-1}\right)\right] \Delta K
$$

\footnotetext{
9 The options data are based upon the following criteria: (i) option prices greater than 3/8; (ii) time to maturity greater than one week; and (iii) at-the-money and out-of-the money options, with moneyness being calculated by the strike price of options divided by the nearest TAIFEX futures transaction price. The intraday data on TAIEX options and futures are obtained from the TEJ database.

${ }^{10}$ Black-Scholes implied volatility is calculated using the one-month deposit rate of the First Bank of Taiwan as a proxy for the risk-free rate, which is obtained from the Central Bank of Taiwan.
} 
where $\Delta K=\left(K_{\max }-K_{\min }\right) / m, K_{i}=K_{\min }+i \Delta K$ for $0 \leq i \leq m$, and $g\left(T, K_{i}\right)=[C(T, K)-$ $\left.\max \left(0, S_{0}-K\right)\right] / K_{i}^{2}$. Therefore, model-free implied volatility $(M F)$ is the square root of Equation (4).

The second volatility estimate is based upon a GARCH model. We collect the daily TAIEX futures returns from the TEJ database and assume that the return series process is an $\operatorname{ARMA}(p, q)-\operatorname{GARCH}(1,1)$ model, as follows:

$$
\begin{gathered}
R_{t}=a_{0}+\sum_{i=1}^{p} \theta_{i} R_{t-i}+\sum_{j=1}^{q} \vartheta_{j} e_{t-j}+e_{t} \\
v_{t}=\alpha_{0}+\alpha_{1} e_{t-1}^{2}+\alpha_{2} v_{t-1}
\end{gathered}
$$

where $R_{t-i}$ refers to the returns of TAIEX futures at time $t-i$, with $i=1 \ldots \mathrm{p} ; e_{t}$ is the residual, with normal distribution, mean zero and time-varying variance, $v_{t}$, with the value of $v_{t}$ being the expected conditional volatility, $C V$, at date $t ; C V$ is generated by taking the square root of the annualized standard deviation multiplied by 252 .

$\operatorname{An} \operatorname{ARMA}(p, q)$ model is adopted in the present study as the means of adjusting the daily return series for potential serial correlation within the data. Our results reveal that an $\operatorname{ARMA}(1,2)-\operatorname{GARCH}(1,1)$ model fits the data well, with no significant serial correlation being found to exist between the normalized raw data and the squared residuals.

The third volatility estimate used in this study is realized volatility $(R V)$. We obtain the five-minute index returns for the Taiwan Weighted Stock Index (TWSE) 
from the TEJ database, and assume that the index return follows an $\operatorname{ARMA}(1,2)$

process. Realized volatility can therefore be expressed as:

$$
\mathrm{RV}_{\mathrm{t}, \mathrm{T}}=\sqrt{\frac{252}{\mathrm{~T}-\mathrm{t}} \sum_{\mathrm{i}=1}^{\mathrm{T}-\mathrm{t}} \sigma_{\mathrm{t}+\mathrm{i}}^{2}}
$$

where $\sigma_{t+i}^{2}=\sum_{\mathrm{k}=1}^{270} \varepsilon_{\mathrm{k}, \mathrm{t}+\mathrm{i}}^{2}$ refers to the sum of the return innovations for each 270-minute interval within each trading day.

The daily series of the three volatility measures during the full sample period from 3 July 2006 to 31 December 2008 are illustrated in Figure 1. From our observations of the three volatility estimates, it is clear that model-free volatility exhibits the greatest variability, with greater fluctuations being found in each of the volatility levels in the post-subprime crisis period.

$<$ Figure 1 is inserted about here>

\subsection{Model Specification}

We examine the ways in which volatility affects the trading demand for speculative and hedging purposes by adopting the empirical regression model proposed in Pan et al. (2003), which is expressed as:

$$
T D_{t}=\alpha+\beta T D_{t-1}+\gamma \sigma_{t}+\varepsilon_{t}
$$

where $T D_{t}$ refers to the trading demand on trading day $t$, respectively measured for speculation and hedging purposes by the speculation index $(S I)$ and hedging pressure 
$(H P) ; \sigma_{t}$ represents one of the three volatility measures, as described in the previous section, with lagged trading demand also being included as a control for potential serial correlation effects. We expect to find that the trading demand for speculative activities will have a negative correlation with volatility, consistent with the findings of Peck (1981). Conversely, we expect to find that the trading demand for hedging purposes will have a positive correlation with volatility, essentially because of the demand amongst investors for hedging their spot positions when there is greater volatility in the market (Chen, Cuny and Haugen, 1995).

The next stage of our analysis involves an examination of the relationship between trading demand and volatility whilst separating the temporary order imbalance from trading activities; thus, the temporary order imbalance measure 'net buying pressure' $N B P$ is included in Equation (8) as a control variable. We also control for the market liquidity measure 'bid-ask spread', essentially because trading demand will be affected by trading costs; that is, if the bid-ask spread is large, it will reduce the trading incentives of both speculators and hedgers (Grossman and Miller, 1988; Lehmann and Modest, 1994). The regression model is expressed as:

$$
\begin{aligned}
T D_{t} & =\alpha+\beta T D_{t-1}+\gamma \sigma_{t}+\delta N B P a t m c_{t}+\eta N B P o t m c_{t} \\
& +\varphi N B \text { Patmp }_{t}+\omega N B P o t m p_{t}+\lambda B i d \_A S K_{t}+\varepsilon_{t}
\end{aligned}
$$

where NBPatmc, NBPotmc, NBPatmp and NBPotmp respectively refer to the net 
buying pressure for the moneyness categories of ATM calls, OTM calls, ATM puts and OTM puts; Bid-Ask is the spread in the bid and ask prices, as measured by the aggregation of bid-ask spread across all options contracts weighted by the corresponding value of their Black-Scholes Delta for each moneyness category, $M=$ ATM and OTM, as follows: ${ }^{11}$

$$
\begin{gathered}
\text { Bid_Ask }_{t}^{M}=\frac{1}{N} \sum_{i=1}^{N} \text { Bid_Ask of call option contract } \text { colta }_{i} \times \text { Del }_{i} \\
+\frac{1}{N} \sum_{i=1}^{N} \text { Bid_Ask of put option contract }{ }_{i} \times \text { Delta }_{i}
\end{gathered}
$$

where $N$ is the number of options contracts in each trading day $t$ for option moneyness category $M$; and Delta $i$ is computed by $N\left(d_{1}\right) /-N\left(-d_{1}\right)$, which is modified from the Black-Scholes model.

The net buying pressure $(N B P)$ measures the temporary order imbalance (which has the effect of reducing the trading demand amongst both hedgers and speculators). If the impact of volatility on trading demand were to be permanent, then we would observe a significant relationship between volatility and trading demand, even when controlling for any temporary order imbalance.

In the second extension of the present study, we examine the ways in which volatility affects trading demand during periods of extreme market stress; for example, during the 2007 subprime mortgage crisis period. With the global economy having

\footnotetext{
11 The TAIFEX options trading system discloses the five best bid and ask prices, which are available from the TEJ database. We use the first best bid and ask prices as a proxy for the quotes of market makers.
} 
been plunged into recession in the latter half of 2007, uncertainty and volatility also plagued the Taiwan stock market; thus, the willingness of investors to trade in derivatives fell sharply as they tried to avoid increased risk and financial losses.

Although these factors will reduce the trading demand in the options market for speculative activities, there may be an increase in such demand for hedging purposes, since hedgers have greater incentives to buy put options and sell call options, given the increase in risk in the underlying asset; the following dummy variable is therefore included in Equation (9) to distinguish between the pre- and post-subprime periods:

$$
\begin{aligned}
& T D_{t}=\alpha+\beta T D_{t-1}+\gamma \sigma_{t}+\delta \sigma_{t} D_{\text {crisis }}+\eta N B P a t m c_{t}+\varphi N B P o t m c_{t} \\
& +\omega N B \text { Patmp }_{t}+\lambda N B \text { Potmp }_{t}+\xi \text { Bid_ASK }_{t}+\varepsilon_{t}
\end{aligned}
$$

where $D_{\text {crisis }}$ takes the value of 1 if the sample belongs to Sub-period II (August 2007 to December 2008); otherwise 0. If the impact of volatility on trading demand was altered significantly as a result of the subprime mortgage crisis, then we should find that the $\delta$ coefficient would be significantly different from zero.

\section{Empirical Results}

The relationship between volatility and the trading demand of speculators and hedgers is reported in Table 3, from which we can see that the trading demand of speculators (hedgers) is negative (positive), with no significant association with an increase in volatility. This finding remains robust throughout the results of our three 
volatility measures; thus, our results provide little evidence of any impact of volatility on trading demand in the TAIEX options market, which is inconsistent with the prior finding on the futures markets (Wang, 2002; Pan et al., 2003).

$<$ Table 3 is inserted about here>

As shown in Table 4, the main results are still unchanged when considering the impact of temporary order imbalance on trading demand; it is, however, interesting to find that the temporary order imbalance measures have significant correlations with trading demand, particularly the OTM call effects on speculative trading activities, and the OTM call and ATM put effects on hedging activities. As noted earlier, the temporary order imbalance reduces the incentive to trade amongst both types of traders, thereby reducing the trading demand; thus, a negative relationship is discernible between net buying pressure and trading demand.

$<$ Table 4 is inserted about here>

After combining the findings reported in Tables 3 and 4, we find that the impact of volatility on trading demand in the options market is more consistent with the 'arbitrage limit' hypothesis (Bollen and Whaley, 2004); that is, an increase in volatility does not necessarily have any direct effect on trading demand, since such demand may actually be attributable to the rise in supply of options due to market fluctuations. Our findings therefore go some way towards explaining the insignificant results reported 
in Pan et al. (2003). Furthermore, the bid-ask spread, which measures the liquidity of the options market, provides an indication of the trading costs faced by investors. As expected, the bid-ask spread is found to have a negative correlation with trading demand, albeit with no statistical significance.

In our final investigation, we examine the impact of volatility on trading demand under extreme financial conditions, such as the 2007 subprime mortgage crisis. A dummy variable was included in Equation (11) to separate the full sample into two sub-periods surrounding the outbreak of the subprime crisis. The trading demand for speculators is shown in Panel A of Table 5 where the results on model-free volatility are found to have a significantly negative correlation with an increase in volatility in the post-subprime crisis period. The model-free volatility measure is also found to be a better volatility estimate than the other two measures, given that the potential problem of model misspecification is totally eliminated, as noted in Section 3.1.

$<$ Table 5 is inserted about here>

Our results provide evidence to show that only the trading demand of speculators was directly affected by the increased volatility in the options market during the subprime crisis, with our earlier results on the impact of temporary order imbalances on trading demand again remaining robust; that is, we find that the net buying pressure of OTM calls has a significantly negative correlation with the trading demand 
of speculators, whilst OTM calls and ATM puts are found to have a significantly negative correlation with the trading demand of hedgers.

In summary, we find little evidence of volatility having had any impact on trading demand amongst either speculators or hedgers; however, the temporary order imbalance measure, 'net buying pressure', is found to have explanatory power on the trading demand of both speculators and hedgers, particularly with regard to the net buying pressure of OTM calls and ATM puts. We also find evidence of changes in the trading activities of speculators in the post-subprime crisis period; such traders are found to have become more risk-averse, resulting in a reduction in their option positions when faced with an increase in risk in the underlying asset.

\section{Conclusions}

We examine the ways in which trading demand was affected by volatility around the 2007 subprime mortgage crisis, thereby extending the work of Pan et al. (2003). Decomposition of the trading demand from temporary order imbalances reveals a significantly negative correlation between temporary net buying pressure and trading demand, which implies that temporary order imbalances discourage trading activity. We also confirm a negative correlation between liquidity and trading demand, essentially because the larger bid-ask spread raises the trading costs for both types of investors.

The main finding of this study is our evidence of changes in the trading activities 
of speculators following the 2007 subprime mortgage crisis. The trading demand amongst such traders is found to have been reduced in a more volatile market, a result which remains robust after controlling for temporary order imbalances and market liquidity under the investigative framework of model-free volatility; this has been found in our study to provide more accurate estimates of volatility than the other models, due to the absence of any potential model misspecification. 


\section{REFERENCES}

Bessembinder, H. and P.J. Seguin (1992), 'Futures Trading Activity and Stock Price Volatility', Journal of Finance, 47: 2015-34.

Bollen, N.B. and R.E. Whaley (2004), 'Does Net Buying Pressure Affect the Shape of Implied Volatility Functions?', Journal of Finance, 59: 711-54.

Birru, J. and S. Figlewski (2012), 'Anatomy of a Meltdown: The Risk-neutral Density of the S\&P 500 in the Fall of 2008', Journal of Financial Market, 15: 151-80.

Cao, H.H. and H. Ou-Yang (2009), 'Differences of Opinion of Public Information and Speculative Trading in Stocks and Options', Review of Financial Studies, 22: 299-335.

Chaput, J.S. and L.H. Ederington (2003), 'Option Spread and Combination Trading', Journal of Derivatives, 10: 70-88.

Chaput, J.S. and L.H. Ederington (2005), 'Volatility Trade Design', Journal of Futures Markets, 25: 243-79.

Chatrath, A., S. Ramchander and F. Song (1995b), 'Does options trading lead to greater cash market volatility?' , Journal of Futures Markets, 15:785- 803.

Chen, N.F., C.J. Cuny and R.A. Haugen (1995), 'Stock Volatility and the Levels of Basis and Open Interest in Futures Contracts', Journal of Finance, 50: 281-300.

Chang, C., P. Hsieh and Y. Wang (2010), 'Information Content of Options Trading Volume for Future Volatility: Evidence from the Taiwan Options Market', Journal of Banking and Finance, 33: 174-83.

de Roon, F.A., T.E. Nijman and C. Veld (2000), 'Hedging Pressure Effects in Futures Markets', Journal of Finance, 55: 1437-56. 
Fahlenbrach, R. and P. Sandas (2010), 'Does Information Drive Trading in Option Strategies?', Journal of Banking and Finance, 34: 2370-85.

Grossman, S.J. and M.H. Miller (1988), 'Liquidity and Market Structure', Journal of Finance, 43: 617-33.

Hagelin, N. (2000), 'Index option market activity and cash market volatility under different market conditions: an empirical study from Sweden', Applied Financial Economics, 10:597-613.

Jiang, G.J. and Y.S. Tian (2005), 'Model-free Implied Volatility and Its Information Content', Review of Financial Studies, 18: 1305-42.

Lee, C. and M. Ready (1991), 'Inferring Trade Direction from Intraday Data', Journal of Finance, 46: 733-46.

Lehmann, B. and D.M. Modest (1994), 'Trading and Liquidity on the Tokyo Stock Exchange: A Bird's Eye View', Journal of Finance, 49: 951-84.

Ni, S.X., J. Pan and A.M. Poteshman (2008), 'Volatility Information Trading in the Options Market', Journal of Finance, 63: 1059-91.

Pan, M.S., Y.A. Liu and H.J. Roth (2003), 'Volatility and Trading Demand in Stock Index Futures', Journal of Futures Markets, 23: 399-414.

Park, T. H., L. N. Switzer and R. Bedrossian (1999), 'The interactions between trading volume and volatility: Evidence from the equity options markets', Applied Financial Economics, 9: 627-637.

Peck, A.E. (1981), 'Measures and Price Effects of Changes in Speculation on the Wheat, Corn and Soybean Futures Markets', In Chicago Board of Trade (eds.), 
Research on Speculation, Chicago: Chicago Board of Trade, pp. 138-49.

Shiu, Y.M., G.G. Pan, S.H. Lin and T.C. Wu (2010), 'Impact of Net Buying Pressure on Changes in Implied Volatility: Before and After the Onset of the Subprime Crisis’, Journal of Derivatives, 17: 54-66.

Wang, C. (2002), 'Information, Trading Demand and Futures Price Volatility', Financial Review, 37: 295-316.

Working, H. (1960), 'Speculation on Hedging Markets', Food Research Institute Studies, 1: 185-270. 


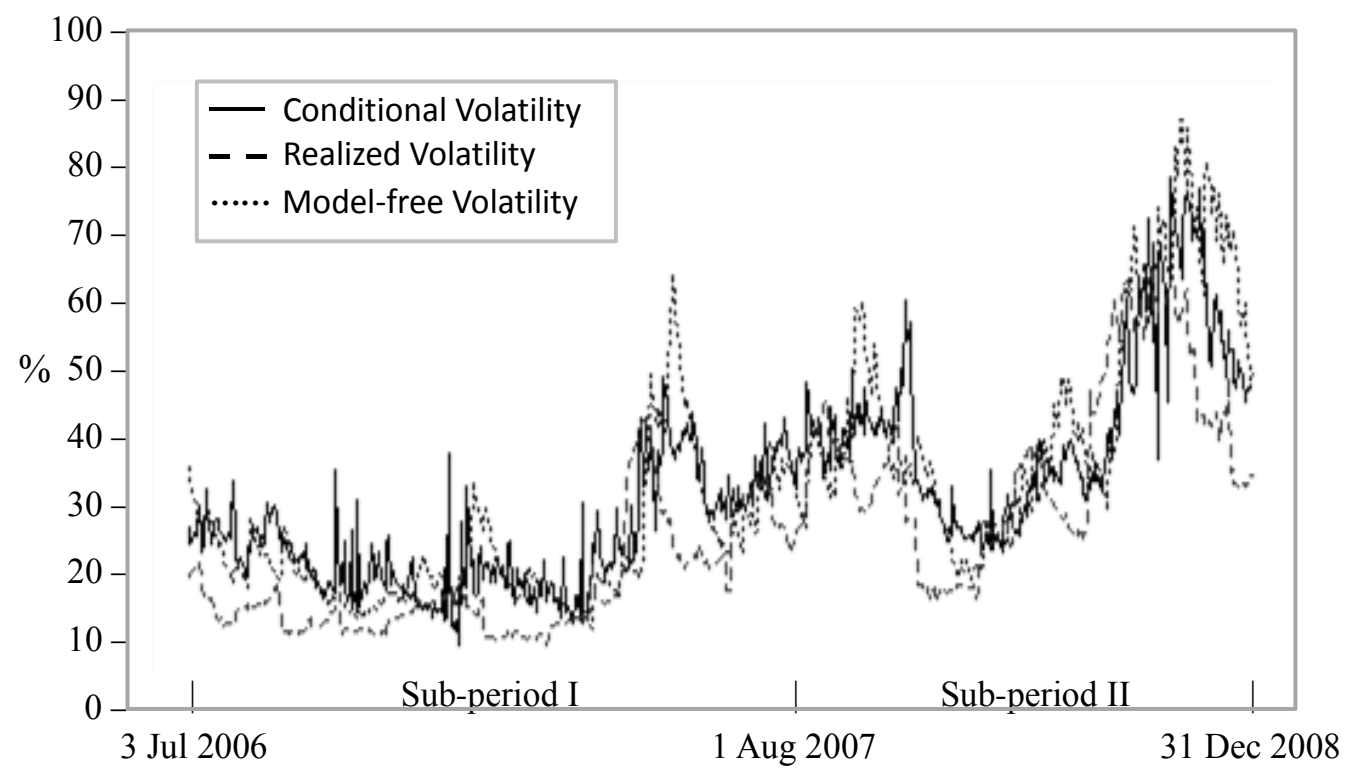

Figure 1 Time-series of the three volatility measures

Notes:

a This figure illustrates the three daily interval volatility measures, comprising of: (i) model-free volatility; (ii) conditional volatility, which is estimated by modeling TAIEX index futures returns as an ARMA $(1,2)$-GARCH $(1,1)$ model; and (iii) realized volatility, which is estimated using TWSE index returns as an ARMA $(1,2)$ model.

b The sample period runs from 3 July 2006 to 31 December 2008, with the period from 3 July 2006 to 31 July 2007 being taken as Sub-period I, and the period from 1 August 2007 to 31 December 2008 being taken as Sub-period II. 
Table 1 Summary statistics of trading demand

This table reports the summary statistics for large open interest and trading demand. SL (SS) indicates the long (short) positions adopted for net speculative activities, whilst $H L(H S)$ indicates the long (short) positions adopted for hedging purposes. $S I$ is the trading demand for speculative activities, which is defined as $1+S L /(H L+H S) \ldots$ if $H L \geq H S$, and as $1+S S /(H L+H S) \ldots$ if $H L<H S$, whilst $H P$ is the trading demand for hedging purposes, which is defined as $(H S-H L) /(H L+H S)$. The sample period runs from 3 July 2006 to 31 December 2008, with the period from 3 July 2006 to 31 July 2007 being taken as Sub-period I, and the period from 1 August 2007 to 31 December 2008 being taken as Sub-period II. All of the figures reported in the table are in units of 10,000 contracts.

\begin{tabular}{|c|c|c|c|c|c|c|}
\hline \multirow{2}{*}{ Variables } & \multicolumn{4}{|c|}{ Large Open Interest } & \multicolumn{2}{|c|}{ Trading Demand } \\
\hline & $S L$ & SS & $H L$ & $H S$ & $S I$ & $H P$ \\
\hline \multicolumn{7}{|c|}{ Panel A: Full Sample Period } \\
\hline Mean & 19.7558 & 18.9295 & 9.2317 & 9.1563 & 2.2506 & -0.0207 \\
\hline Median & 16.4098 & 18.6119 & 9.1228 & 8.8161 & 1.8582 & -0.0053 \\
\hline Std. Dev. & 10.7948 & 6.4378 & 4.0591 & 4.7469 & 1.0494 & 0.2294 \\
\hline $\operatorname{Max}$ & 63.3865 & 43.2073 & 22.8412 & 22.7398 & 8.9956 & 0.5976 \\
\hline Min & 4.1472 & 3.8209 & 0.9945 & 1.0894 & 1.2496 & -0.6284 \\
\hline No. of Obs. & 624 & 624 & 624 & 624 & 624 & 624 \\
\hline \multicolumn{7}{|c|}{ Panel B: Sub-period I } \\
\hline Mean & 17.7475 & 20.5989 & 7.8811 & 8.0556 & 2.6836 & -0.0462 \\
\hline Median & 16.8369 & 20.0049 & 8.1941 & 7.6383 & 2.1554 & -0.0011 \\
\hline Std. Dev. & 5.5901 & 4.8154 & 3.8911 & 5.6423 & 1.3334 & 0.2464 \\
\hline Max & 31.0202 & 31.8327 & 18.2064 & 22.7398 & 8.9956 & 0.5195 \\
\hline Min & 7.4517 & 7.5641 & 0.9945 & 1.0894 & 1.4383 & -0.6284 \\
\hline No. of Obs. & 269 & 269 & 269 & 269 & 269 & 269 \\
\hline \multicolumn{7}{|c|}{ Panel C: Sub-period II } \\
\hline Mean & 21.2776 & 17.6645 & 10.2552 & 9.9904 & 1.9224 & -0.0013 \\
\hline Median & 16.1665 & 16.6469 & 10.2618 & 9.2965 & 1.7325 & -0.0144 \\
\hline Std. Dev. & 13.2677 & 7.1876 & 3.8856 & 3.7330 & 0.5845 & 0.2140 \\
\hline $\operatorname{Max}$ & 63.3865 & 43.2073 & 22.8412 & 19.7800 & 3.8192 & 0.5976 \\
\hline Min & 4.1472 & 3.8209 & 1.1728 & 2.4188 & 1.2496 & -0.4163 \\
\hline No. of Obs. & 355 & 355 & 355 & 355 & 355 & 355 \\
\hline
\end{tabular}


Table 2 Summary statistics of net options contract purchases and net buying pressure

This table reports the summary statistics on net options contract purchases and net buying pressure. Net purchases for each options contract (NPC) are calculated by the number of buyer-initiated minus seller-initiated contracts. Net buying pressure $(N B P)$ is the equally-weighted average of delta-weighted net purchases across all options contracts in the at-the-money (ATM) and out-of-the-money (OTM) moneyness categories. The sample period runs from 3 July 2006 to 31 December 2008 , with the period from 3 July 2006 to 31 July 2007 being taken as Sub-period I, and the period from 1 August 2007 to 31 December 2008 being taken as Sub-period II.

\begin{tabular}{|c|c|c|c|c|c|c|c|c|}
\hline \multirow{3}{*}{ Variables } & \multicolumn{4}{|c|}{ Call Options } & \multicolumn{4}{|c|}{ Put Options } \\
\hline & \multicolumn{2}{|c|}{ ATM } & \multicolumn{2}{|c|}{ OTM } & \multicolumn{2}{|c|}{ ATM } & \multicolumn{2}{|c|}{ OTM } \\
\hline & $N P C$ & $N B P$ & $N P C$ & $N B P$ & $N P C$ & $N B P$ & $N P C$ & $N B P$ \\
\hline \multicolumn{9}{|c|}{ Panel A: Full Sample Period } \\
\hline Mean & -65.97 & -12.67 & -171.68 & -7.80 & -30.42 & -1.93 & -100.76 & -4.66 \\
\hline Median & -18.00 & -17.58 & -36.00 & -0.83 & -11.00 & 11.87 & -41.50 & 0.32 \\
\hline Std. Dev. & $1,004.52$ & 244.15 & 956.64 & 73.15 & 758.26 & 185.29 & 711.54 & 78.28 \\
\hline $\operatorname{Max}$ & 8,631 & 1,122 & 5,638 & 439 & 7,108 & 913 & 5,574 & 310 \\
\hline Min & $-10,080$ & -982 & $-14,833$ & -497 & $-7,986$ & $-1,882$ & $-3,874$ & $-1,331$ \\
\hline No. of Obs. & 3,237 & 624 & 2,903 & 624 & 3,237 & 624 & 3,094 & 608 \\
\hline \multicolumn{9}{|c|}{ Panel B: Sub-period I } \\
\hline Mean & -107.04 & -20.91 & -126.46 & 1.68 & -65.40 & 0.32 & -216.66 & 2.90 \\
\hline Median & -35.00 & -38.42 & -2.00 & 0.42 & -20.00 & 23.32 & -120.00 & 0.54 \\
\hline Std. Dev. & 1374.78 & 321.86 & 1025.80 & 48.09 & 1024.93 & 235.01 & 781.75 & 30.00 \\
\hline $\operatorname{Max}$ & 7,169 & 1,122 & 5,638 & 240 & 7,108 & 415 & 4,498 & 153 \\
\hline Min & $-10,080$ & -982 & $-8,050$ & -262 & $-7,066$ & -1882 & $-3,874$ & -173 \\
\hline No. of Obs. & 1,383 & 269 & 1,038 & 269 & 1,381 & 269 & 1,418 & 269 \\
\hline \multicolumn{9}{|c|}{ Panel C: Sub-period II } \\
\hline Mean & -35.34 & -6.42 & -196.85 & -14.99 & -4.40 & -3.64 & -2.70 & -10.66 \\
\hline Median & -12.00 & -11.80 & -68.00 & -6.20 & -6.00 & 5.83 & -6.00 & -0.25 \\
\hline Std. Dev. & 591.92 & 162.43 & 915.20 & 86.87 & 468.97 & 136.39 & 630.01 & 101.04 \\
\hline $\operatorname{Max}$ & 8,631 & 971 & 4,547 & 439 & 3,440 & 913 & 5,574 & 310 \\
\hline Min & $-5,157$ & -874 & $-14,833$ & -497 & $-7,986$ & -940 & $-3,737$ & $-1,331$ \\
\hline No. of Obs. & 1,854 & 355 & 1,865 & 355 & 1,856 & 355 & 1,676 & 339 \\
\hline
\end{tabular}


Table 3 Trading demand and volatility of speculators and hedgers

This table reports the estimates of the effects of the daily trading demand of speculators and hedgers on TAIEX options volatility from 3 July 2006 to 31 December 2008 based upon the following regression model:

$$
T D_{t}=\alpha+\beta T D_{t-1}+\gamma \sigma_{t}+\varepsilon_{t}
$$

where $T D_{t}$ is the trading demand on day $t$; and $\sigma_{t}$ represents the three volatility measures comprising of (i) conditional volatility $(C V)$; (ii) model-free volatility $(M F)$; and (iii) realized volatility $(R V)$. The trading demand for speculators, measured as their net speculative position $(S I)$, is defined as $1+S L /(H L+H S) \ldots$ if $H L \geq H S$, and defined as $1+S S /(H L+H S) \ldots$ if $H L<H S$, whilst the trading demand for hedgers is measured as the hedging pressure $(H P)$, defined as $(H S-H L) /(H L+H S)$. The $t$-statistics are computed using White (1980) heteroskedasticity consistent estimates. * indicates statistical significance at the $10 \%$ level; $* *$ indicates statistical significance at the $5 \%$ level; and $* * *$ indicates statistical significance at the $1 \%$ level.

\begin{tabular}{|c|c|c|c|c|c|c|}
\hline \multirow{3}{*}{$\begin{array}{c}\text { Investor } \\
\text { Types }\end{array}$} & \multicolumn{6}{|c|}{ Volatility Measures } \\
\hline & \multicolumn{2}{|c|}{$\sigma_{t}=C V_{t}$} & \multicolumn{2}{|c|}{$\sigma_{t}=M F_{t}$} & \multicolumn{2}{|c|}{$\sigma_{t}=R V_{t}$} \\
\hline & Coeff. & $t$-stat. & Coeff. & $t$-stat. & Coeff. & $t$-stat. \\
\hline \multicolumn{7}{|c|}{ Panel A: Speculators } \\
\hline$\alpha$ & 0.1379 & $2.03 * *$ & 0.1331 & $1.92 *$ & 0.1657 & $2.25^{* *}$ \\
\hline$\beta$ & 0.9446 & $33.22 * * *$ & 0.9463 & $33.41 * * *$ & 0.9411 & $32.96 * * *$ \\
\hline$\gamma$ & -0.0548 & -0.62 & -0.0501 & -0.51 & -0.1510 & -1.04 \\
\hline Adj. $\mathrm{R}^{2}$ & \multicolumn{2}{|c|}{0.8923} & \multicolumn{2}{|c|}{0.8919} & \multicolumn{2}{|c|}{0.8925} \\
\hline \multicolumn{7}{|c|}{ Panel B: Hedgers } \\
\hline$\alpha$ & -0.0083 & -0.99 & -0.0078 & -0.82 & -0.0101 & -1.17 \\
\hline$\beta$ & 0.9220 & $53.59 * * *$ & 0.9231 & $55.20 * * *$ & 0.9219 & $53.54 * * *$ \\
\hline$\gamma$ & 0.0241 & 0.99 & 0.0224 & 0.80 & 0.0370 & 1.16 \\
\hline Adj. $\mathrm{R}^{2}$ & \multicolumn{2}{|c|}{0.8546} & \multicolumn{2}{|c|}{0.8545} & \multicolumn{2}{|c|}{0.8547} \\
\hline
\end{tabular}


Table 4 Trading demand, buying pressure and volatility

This table reports the regression estimates of the effects of daily trading demand amongst speculators and hedgers on the volatility of TAIEX options, when controlling for net buying pressure, with the sample period running from 3 July 2006 to 31 December 2008; the estimation results are based upon the following regression model:

$$
\begin{gathered}
T D_{t}=\alpha+\beta T D_{t-1}+\gamma \sigma_{t}+\delta N B P a t m c_{t}+\eta N B P o t m c_{t} \\
+\varphi N B P a t m p_{t}+\omega N B P o t m p_{t}+\lambda B i d_{-}{ }_{\text {As }} k_{t}+\varepsilon_{t}
\end{gathered}
$$

where NBPatmc, NBPotmc, NBPatmp and NBPotmp respectively represent the net buying pressure for ATM call, OTM call, ATM put and OTM put moneyness categories; Bid-Ask refers to the bid and ask spread measured by the aggregation of bid-ask spread across all option contracts weighted by the corresponding Black-Scholes Delta value for each moneyness category, $M=$ ATM and OTM. The $t$-statistics are computed using White (1980) heteroskedasticity consistent estimates. $*$ indicates statistical significance at the $10 \%$ level; $* *$ indicates statistical significance at the $5 \%$ level; and $* * *$

\begin{tabular}{|c|c|c|c|c|c|c|}
\hline \multirow{3}{*}{$\begin{array}{c}\text { Investor } \\
\text { Types }\end{array}$} & \multicolumn{6}{|c|}{ Volatility Measures } \\
\hline & \multicolumn{2}{|c|}{$\sigma_{t}=C V_{t}$} & \multicolumn{2}{|c|}{$\sigma_{t}=M F_{t}$} & \multicolumn{2}{|c|}{$\sigma_{t}=R V_{t}$} \\
\hline & Coeff. & $t$-stat. & Coeff. & $t$-stat. & Coeff. & $t$-stat. \\
\hline \multicolumn{7}{|c|}{ Panel A: Speculators } \\
\hline$\alpha$ & 0.0999 & 1.58 & 0.1009 & 1.52 & 0.1245 & $1.85^{*}$ \\
\hline$\beta$ & 0.9589 & $34.60 * * *$ & 0.9601 & $34.46^{* * *}$ & 0.9559 & $34.40^{* * *}$ \\
\hline$\gamma$ & -0.0450 & -0.63 & -0.0564 & -0.68 & -0.1331 & -1.10 \\
\hline$\delta$ & 0.0000 & -0.19 & 0.0000 & -0.22 & 0.0000 & -0.15 \\
\hline$\eta$ & -0.0006 & $-2.23 * *$ & -0.0006 & $-2.25^{* *}$ & -0.0006 & $-2.24 * *$ \\
\hline$\varphi$ & 0.0000 & 0.15 & 0.0000 & 0.12 & 0.0000 & 0.18 \\
\hline$\omega$ & 0.0001 & 0.31 & 0.0001 & 0.28 & 0.0000 & 0.21 \\
\hline$\lambda$ & -0.0183 & -1.01 & -0.0183 & -1.02 & -0.0143 & -0.78 \\
\hline Adj. $R^{2}$ & \multicolumn{2}{|c|}{0.9055} & \multicolumn{2}{|c|}{0.9052} & \multicolumn{2}{|c|}{0.9056} \\
\hline
\end{tabular}
indicates statistical significance at the $1 \%$ level.

Panel B: Hedgers

\begin{tabular}{ccccccc}
$\alpha$ & -0.0088 & -1.03 & -0.0079 & -0.83 & -0.0113 & -1.28 \\
$\beta$ & 0.9210 & $52.81^{* * *}$ & 0.9223 & $54.40^{* * *}$ & 0.9206 & $52.66^{* * *}$ \\
$\gamma$ & 0.0256 & 1.06 & 0.0231 & 0.82 & 0.0422 & 1.28 \\
$\delta$ & 0.0000 & -0.24 & 0.0000 & -0.24 & 0.0000 & -0.26 \\
$\eta$ & -0.0001 & $-1.67^{*}$ & -0.0001 & $-1.66^{*}$ & -0.0001 & $-1.69^{*}$ \\
$\varphi$ & -0.0001 & $-2.16^{* *}$ & -0.0001 & $-2.12^{* *}$ & -0.0001 & $-2.15^{* *}$ \\
$\omega$ & 0.0000 & 0.90 & 0.0000 & 0.97 & 0.0000 & 1.12 \\
$\lambda$ & -0.0019 & -0.34 & -0.0016 & -0.29 & -0.0028 & -0.50 \\
Adj. R & 0.8599 & 0.8598 & \multicolumn{2}{c}{0.8600}
\end{tabular}


Table 5 Trading demand, buying pressure and volatility around the subprime crisis period

This table reports the regression estimates of daily trading demand amongst speculators and hedgers on the volatility of TAIEX options, when controlling for net buying pressure. The full sample period is divided around the subprime crisis period, with the period from 3 July 2006 to 31 July 2007 being taken as Sub-period I, and the period from 1 August 2007 to 31 December 2008 being taken as Sub-period II. The regression model is as follows:

$$
\begin{aligned}
& T D_{t}=\alpha+\beta T D_{t-1}+\gamma \sigma_{t}+\delta \sigma_{t} D_{\text {crisis }}+\eta N B \text { Patmc }_{t}+\varphi N B \text { Potmc }_{t} \\
&+\omega N B \text { Patmp } \\
& t+\lambda N B \text { Potmp } \\
& t
\end{aligned}
$$

where NBPatmc, NBPotmc, NBPatmp and NBPotmp respectively represent the net buying pressure for ATM call, OTM call, ATM put and OTM put moneyness categories; Bid-Ask refers to the bid and ask spread measured by the aggregation of bid-ask spread across all option contracts weighted by the corresponding Black-Scholes Delta value for each moneyness category, $M=$ ATM and OTM. $D_{\text {crisis }}$ is a dummy variable which takes the value of 1 if the sample belongs to Sub-period II; otherwise 0 . The $t$-statistics are computed using White (1980) heteroskedasticity consistent estimates. * indicates statistical significance at the $10 \%$ level; $* *$ indicates statistical significance at the $5 \%$ level; and $* * *$ indicates

\begin{tabular}{|c|c|c|c|c|c|c|}
\hline \multirow{3}{*}{$\begin{array}{c}\text { Investor } \\
\text { Types }\end{array}$} & \multicolumn{6}{|c|}{ Volatility Measures } \\
\hline & \multicolumn{2}{|c|}{$\sigma_{t}=C V_{t}$} & \multicolumn{2}{|c|}{$\sigma_{t}=M F_{t}$} & \multicolumn{2}{|c|}{$\sigma_{t}=R V_{t}$} \\
\hline & Coeff. & $t$-stat. & Coeff. & $t$-stat. & Coeff. & $t$-stat. \\
\hline \multicolumn{7}{|c|}{ Panel A: Speculators } \\
\hline$\alpha$ & 0.0629 & 1.01 & 0.0549 & 0.85 & 0.1215 & $1.92 *$ \\
\hline$\beta$ & 0.9567 & $33.56 * * *$ & 0.9522 & $32.50^{* * * *}$ & 0.9573 & $34.30^{* * * *}$ \\
\hline$\gamma$ & 0.2698 & 1.08 & 0.3796 & 1.51 & -0.1380 & -0.75 \\
\hline$\delta$ & -0.2341 & -1.22 & -0.2993 & $-1.66^{*}$ & 0.0052 & 0.04 \\
\hline$\eta$ & 0.0000 & -0.16 & 0.0000 & -0.37 & 0.0000 & -0.15 \\
\hline$\varphi$ & -0.0006 & $-2.20 * *$ & -0.0006 & $-2.19 * *$ & -0.0006 & $-2.24 * *$ \\
\hline$\omega$ & 0.0000 & 0.14 & 0.0000 & 0.31 & 0.0000 & 0.16 \\
\hline$\lambda$ & 0.0000 & 0.23 & 0.0000 & 0.28 & 0.0000 & 0.21 \\
\hline$\xi$ & -0.0117 & -0.62 & -0.0099 & -0.52 & -0.0146 & -0.77 \\
\hline Adj. $R^{2}$ & \multicolumn{2}{|c|}{0.9058} & \multicolumn{2}{|c|}{0.9056} & \multicolumn{2}{|c|}{0.9055} \\
\hline
\end{tabular}
statistical significance at the $1 \%$ level.

Panel B: Hedgers

\begin{tabular}{lcccccc}
$\alpha$ & -0.0132 & -1.12 & -0.0080 & -0.59 & -0.0201 & $-1.92^{*}$ \\
$\beta$ & 0.9206 & $52.47 * *$ & 0.9225 & $54.29 * * *$ & 0.9179 & $51.69 * * *$ \\
$\gamma$ & 0.0584 & 0.85 & 0.0232 & 0.31 & 0.1279 & $1.92^{*}$ \\
$\delta$ & -0.0240 & -0.50 & 0.0000 & -0.00 & -0.0651 & -1.45 \\
$\eta$ & 0.0000 & -0.22 & 0.0000 & -0.24 & 0.0000 & -0.28 \\
$\varphi$ & -0.0001 & $-1.67 *$ & -0.0001 & $-1.67 *$ & -0.0001 & $-1.69^{*}$ \\
$\omega$ & -0.0001 & $-2.17 * *$ & -0.0001 & $-2.11^{* *}$ & 0.0000 & $-2.05^{* *}$ \\
$\lambda$ & 0.0000 & 0.84 & 0.0000 & 0.97 & 0.0000 & 1.15 \\
$\xi$ & -0.0013 & -0.23 & -0.0017 & -0.30 & -0.0010 & -0.17 \\
Aj. R & \multicolumn{2}{c}{0.8598} & 0.8596 & 0.8602
\end{tabular}

